[Chem. Pharm. Bull.

32( 9$) 3674-3677(1984)]$

\title{
A New Triterpene from Vellozia compacta
}

\author{
Roderick A. Barnes, ${ }^{*} a$ Anibal L. Pereira, ${ }^{a}$ Tereza Cristina V. Scofield,${ }^{a}$ \\ Raimundo Braz Filho ${ }^{b}$ and Angelo C. Pinto ${ }^{a}$ \\ Nucleus of Research on Natural Products ${ }^{a}$ and Department of Chemistry, ${ }^{b}$ \\ Federal University of Rio de Janeiro, Rio de Janeiro \\ 21941, RJ, Brazil
}

(Received November 28, 1983)

\begin{abstract}
A triterpene not previously obtained from natural sources has been isolated from Vellozia compacta and its structure assigned on the basis of spectral data. For confirmation of this assignment, a partial synthesis was carried out. $\beta$-Amyrenyl acetate was oxidized and the resulting ketone reduced to a diol, which, after selective dehydration and reoxidation, furnished the natural product.
\end{abstract}

Keywords__-Vellozia compacta; Velloziaceae; triterpene; oleanane; partial synthesis

As a part of a series of studies of Brazilian plants of the genus Vellozia, we have examined Vellozia compacta MARTIUS ex SCHULTES and identified a number of di- and triterpenes. ${ }^{1-4)}$ In a further investigation of the hexane extract of this plant a triterpene, $\mathrm{C}_{30} \mathrm{H}_{46} \mathrm{O}$, has been isolated. The infrared (IR) spectrum $\left(v=1700 \mathrm{~cm}^{-1}\right)$ shows this substance to be a ketone and the ultraviolet (UV) spectrum is characteristic of a homoannular diene $\left(\lambda_{\max } 283 ; \varepsilon 8.600\right)$. The proton nuclear magnetic resonance $\left({ }^{1} \mathrm{H}-\mathrm{NMR}\right)$ spectrum has an $\mathrm{AB}$ pattern $(\delta=5.6)$ indicating the presence of the structural unit $\mathbf{\square}-\mathrm{C}=\mathrm{CH}-\mathrm{CH}=\mathrm{C}-\mathbf{\square}$. There were also eight singlets due to methyl groups at quaternary carbons. This fact, together with the fragmentation pattern in the mass spectrum (MS), strongly suggested an oleanane skeleton. Major fragments with masses of 255 and 269 could result from cleavage of rings B and D, respectively, in accordance with the observation of Gonzalez, Fraga and Ravelo ${ }^{5)}$ for a diene of the ursane series.

Since there is only one possible location for the diene system in this skeleton we conclude that our triterpene has the structure 1.

The ketone group must be at C-3 from biogenetic considerations and this was confirmed by comparing the carbon-13 nuclear magnetic resonance $\left({ }^{13} \mathrm{C}-\mathrm{NMR}\right)$ spectrum with those of known triterpenes ${ }^{6)}$ (Table I).

A ketone reported to have the structure 1 was prepared by Picard and Spring ${ }^{7)}$ from $\beta$ amyrenyl benzoate, but since there was some controversy ${ }^{7,8}$ about one of the reactions involved, it was decided to carry out an alternate synthesis for confirmation of this structure. $\beta$-Amyrenyl acetate 2 was oxidized to the ketone 3 ; this reaction was analogous to that carried out by Spring and collaborators ${ }^{7)}$ using chromic acid and the corresponding benzoate. However with tert-butyl chromate, the desired ketone was obtained in a much better yield $(85-90 \%){ }^{10)}$

The reduction of the ketone group of $\mathbf{3}$ was even more difficult than expected. Sodium borohydride under mild conditions had no effect, and under forcing conditions it removed the protecting acetate group, leaving the ketone unchanged. However, with lithium aluminum hydride, the diol 4 was obtained in good yield. The reduction was stereospecific, since thin 


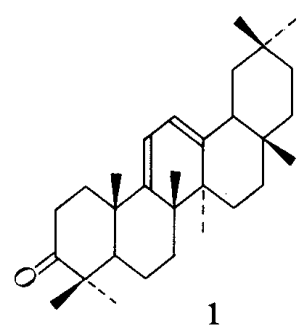

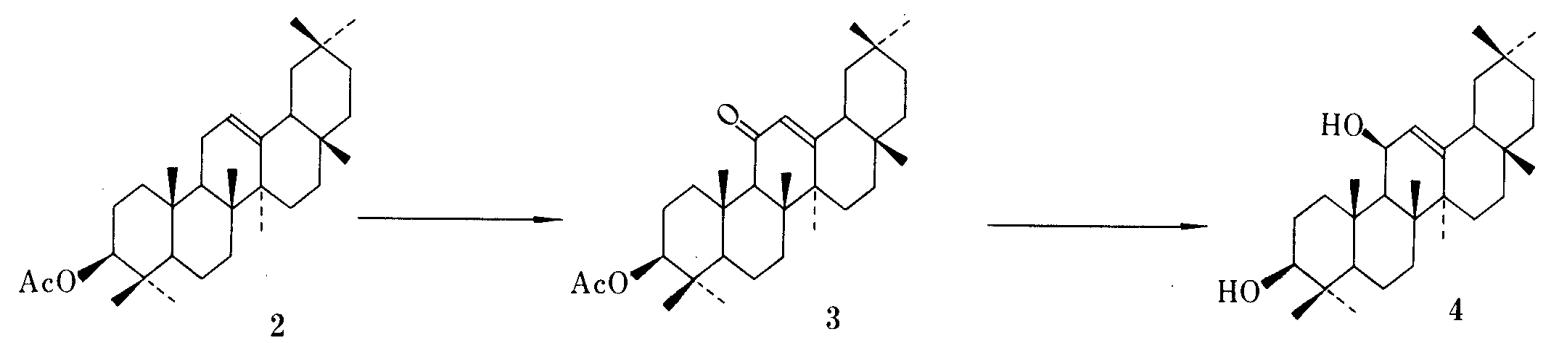

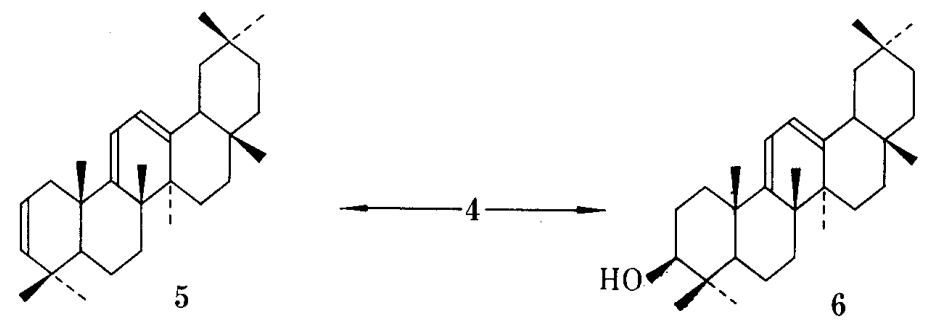

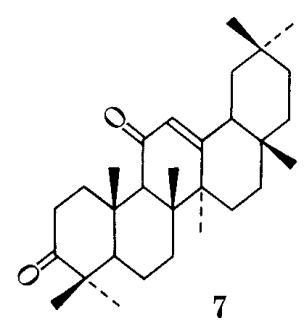

layer chromatography (TLC) showed that a single product had been formed. The angular methyl groups at $\mathrm{C}-8$ and $\mathrm{C}-10$ inhibit the approach of the reagent from the $\beta$ side of the molecule, so that resulting hydroxyl group must be $\beta$ (axial). Since this hydroxyl group is trans to the axial hydrogen at $\mathrm{C}-9$, it was anticipated that dehydration would be more readily effected at this part of the molecule than in ring $\mathrm{A}$. The first attempt at dehydration using phosphorus oxychloride and pyridine at $0^{\circ} \mathrm{C}$ resulted in elimination of both hydroxyl groups to yield the olefin 5 .

No rearrangement of ring A took place under these conditions since the ${ }^{1} \mathrm{H}-\mathrm{NMR}$ spectrum showed the presence of four olefinic hydrogens and the absence of methyl groups linked to an olefinic carbon. Finally it was found that the use of dilute hydrochloric acid to separate the aluminum salts in the preparation of the diol 4, furnished sufficient acid to catalyze the desired dehydration. The alcohol $\mathbf{6}$ obtained in this way was treated with Jones reagent at $0{ }^{\circ} \mathrm{C}$ to form 1 , which was identical to the natural product.

The ease with which the dehydration of 4 occurred suggests that the biogenesis of 1 also involves the formation of $\mathbf{4}$ from $\beta$-amyrin, followed by dehydration and oxidation as in our laboratory synthesis. Evidence that oxidation at C-11 takes place in these plants is furnished by the isolation of the diketone 7 from Vellozia glabra. ${ }^{11)}$ 
TABLE I. ${ }^{13} \mathrm{C}$ Chemical Shifts of Compounds 1, 3 and $\beta$-Amyrin ${ }^{a)}$

\begin{tabular}{|c|c|c|c|}
\hline $\mathrm{C}$ & 1 & 3 & $\beta$-Amyrin \\
\hline 1 & $37.0^{b)}$ & .38 .7 & 28.7 \\
\hline 2 & 34.5 & 23.4 & 27.3 \\
\hline 3 & 217.3 & 80.5 & 79.0 \\
\hline 4 & 47.2 & 38.0 & 38.8 \\
\hline 5 & 51.7 & 54.9 & 55.3 \\
\hline 6 & 19.1 & 18.4 & 18.4 \\
\hline 7 & 31.2 & 32.6 & 32.8 \\
\hline 8 & 40.6 & 43.3 & 38.8 \\
\hline 9 & 152.1 & 61.5 & 47.7 \\
\hline 10 & 38.1 & 36.9 & 37.0 \\
\hline 11 & 117.3 & 201.4 & 23.6 \\
\hline 12 & 120.4 & 127.9 & 121.8 \\
\hline 13 & 147.2 & 170.2 & 145.1 \\
\hline 14 & 42.9 & 45.3 & 41.8 \\
\hline 15 & 27.2 & 26.4 & 26.2 \\
\hline 16 & 25.6 & 26.4 & 27.0 \\
\hline 17 & 32.1 & 32.3 & 32.5 \\
\hline 18 & 45.6 & 47.5 & 47.4 \\
\hline 19 & 46.8 & 45.0 & 46.9 \\
\hline 20 & 31.6 & 31.0 & 31.1 \\
\hline 21 & 34.5 & 34.4 & 34.8 \\
\hline 22 & $37.7^{b)}$ & 36.4 & 37.2 \\
\hline 23 & 26.8 & 28.0 & 28.2 \\
\hline 24 & 21.2 & 16.6 & 15.5 \\
\hline 25 & 20.5 & 15.7 & 15.6 \\
\hline 26 & 19.9 & 17.3 & 16.9 \\
\hline 27 & 25.2 & 23.5 & 26.0 \\
\hline 28 & 28.7 & 28.7 & 28.4 \\
\hline 29 & 33.1 & 33.0 & 33.3 \\
\hline 30 & 23.6 & 23.5 & 23.7 \\
\hline $\mathrm{COO}$ & - & 170.6 & - \\
\hline $\mathrm{CH}_{3}$ & - & 21.2 & - \\
\hline
\end{tabular}

a) The $\delta$ values are in ppm downfield from TMS; the solvent was $\mathrm{CDCl}_{3}$.

b) These assignments may be reversed.

\section{Experimental}

The ${ }^{13} \mathrm{C}-\mathrm{NMR}$ spectra were obtained using a Varian XL-100-12 spectrometer $(25.2 \mathrm{MHz}$, spectral width $5 \mathrm{kHz}$, acquisition time $0.8 \mathrm{~s}$, flip angle $45^{\circ}$ and internal ${ }^{2} \mathrm{H}$ pulse lock). Tetramethylsilyl (TMS) was the internal standard for ${ }^{1} \mathrm{H}-\mathrm{NMR}$. Melting points are uncorrected (Kofler apparatus).

Isolation of 1-Vellozia compacta was collected in the Serra do Cipó in the state of Minas Gerais, Brazil. Stems, roots and leaf sheaths were cut into small pieces and extracted with hexane, and the extract was concentrated in vacuo. The crude concentrate was chromatographed on silica gel (Merck, 0.05-0.20 mm); elution with $1 \%$ AcOEt in hexane provided 1 , which was recrystallized from hexane. $\mathrm{mp} 206-208^{\circ} \mathrm{C}$.

$$
[\alpha]^{25}=\frac{373}{589} \frac{393}{578} \frac{463}{546} \frac{998}{436} \frac{2338}{365} \mathrm{~nm} \quad\left(c=1.07, \mathrm{CHCl}_{3}\right) .
$$

$\mathrm{UV} \lambda_{\max }^{\mathrm{CH}_{2} \mathrm{Cl}_{2}} 283 \mathrm{~nm}(\varepsilon=8560)$. IR $v_{\max }^{\mathrm{KBr}} \mathrm{cm}^{-1}: 1700,830 .{ }^{1} \mathrm{H}-\mathrm{NMR}\left(100 \mathrm{MHz}, \mathrm{CDCl}_{3}\right) \delta: 0.90(6 \mathrm{H}, \mathrm{s}), 1.00(3 \mathrm{H}, \mathrm{s}), 1.02$ $(3 \mathrm{H}, \mathrm{s}), 1: 04(3 \mathrm{H}, \mathrm{s}), 1.08(3 \mathrm{H}, \mathrm{s}), 1.20(3 \mathrm{H}, \mathrm{s}), 1.28(3 \mathrm{H}, \mathrm{s}), 2.5(2 \mathrm{H}, \mathrm{m}), 5.51(1 \mathrm{H}, \mathrm{d}, J=6 \mathrm{~Hz}), 5.63(1 \mathrm{H}, \mathrm{d}, J=6 \mathrm{~Hz})$. MS $m / e(\%): 422\left(100, \mathrm{M}^{+}\right), 407$ (11), 324 (1), 269 (27), 255 (31), 171 (20), 145 (20), 143 (18), 133 (37), 118 (28), 95 (48), 69 (63), 55 (70), 41 (95).

$\boldsymbol{\beta}$-Amyrenyl Acetate (2) A solution of $\beta$-amyrin $\left(175 \mathrm{mg}\right.$ ) in acetic anhydride (freshly distilled from $\mathrm{CaC}_{2}$ ) was treated with a catalytic quantity $(10 \mathrm{mg})$ of 4-dimethylaminopyridine and the reaction mixture was allowed to stand for $12 \mathrm{~h}$ at room temperature. Excess acetic anhydride was distilled off in vacuo and the residue was dried to 
constant weight in a vacuum desiccator over sodium hydroxide, giving $192 \mathrm{mg}(100 \%)$ of product, which was crystallized from ethyl acetate-acetic acid. $\mathrm{mp} 237-240^{\circ} \mathrm{C}$.

11-Keto- $\beta$-amyrenyl Acetate (3)—-tert-Butyl chromate ${ }^{12)}(2.4 \mathrm{ml})$ was added to a solution of $2(127 \mathrm{mg})$ in carbon tetrachloride $(12 \mathrm{ml})$, acetic acid $(4 \mathrm{ml})$ and acetic anhydride $(2 \mathrm{ml})$. This solution was heated at reflux temperature for $6 \mathrm{~h}$ then cooled and diluted with chloroform $(30 \mathrm{ml})$. The mixture was washed with water $(20 \mathrm{ml})$, oxalic acid solution $(3 \times 20 \mathrm{ml}, 5 \%)$ and saturated sodium bicarbonate solution $(20 \mathrm{ml})$, then dried over sodium sulfate. The solvents were evaporated off and the residue was crystallized from acetic acid. The purified product

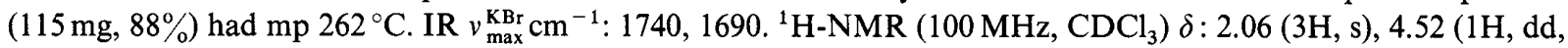
$J=10$ and $6 \mathrm{~Hz}), 5.56(1 \mathrm{H}, \mathrm{s})$.

Reduction of 11-Keto- $\beta$-amyrenyl Acetate- Sodium borohydride $(300 \mathrm{mg})$ was added to a solution of the ketone $3(110 \mathrm{mg})$ in 2-methoxyethanol $(4 \mathrm{ml})$ and dimethylformamide $(5 \mathrm{ml})$, and the reaction mixture was stirred at $50^{\circ} \mathrm{C}$ for $16 \mathrm{~h}$. Dilution with water precipitated a solid whose IR spectrum showed a single carbonyl peak $\left(1671 \mathrm{~cm}^{-1}\right)$. This substance, after reaction with acetic anhydride, yielded the ketone 3 .

A solution of $\mathbf{3}(84 \mathrm{mg})$ in dry tetrahydrofuran (THF) $(10 \mathrm{ml})$ was added to a suspension of lithium aluminum hydride (30 mg) in THF ( $5 \mathrm{ml})$. The mixture was stirred at reflux temperature for $8 \mathrm{~h}$, then cooled. Water was added slowly to the reaction mixture, forming a flocculent precipitate which was washed with small portions of ether $(4 \times 15 \mathrm{ml})$. The combined ether solution was washed with water, dried over sodium sulfate and concentrated, finally in vacuo. The residual solid, $4,(62 \mathrm{mg}, 80 \%)$ was characterized by TLC (single spot) and IR: $v_{\max }^{\mathrm{KBr}} \mathrm{cm}^{-1}: 3225$ (br), no carbonyl peaks.

Dehydration of 4-A solution of $4(40 \mathrm{mg})$ in dry pyridine $(1.5 \mathrm{ml})$ was stirred at $0{ }^{\circ} \mathrm{C}$ while phosphorus oxychloride $(1 \mathrm{ml})$ was added dropwise. After an hour, water was added carefully with continued cooling. The reaction mixture was diluted with chloroform and the solution washed with water, dried and concentrated to yield 5 as an oil. ${ }^{1} \mathrm{H}-\mathrm{NMR}\left(100 \mathrm{MHz}, \mathrm{CDCl}_{3}\right) \delta 4.3-4.6(4 \mathrm{H}, \mathrm{m}), \mathrm{CH}_{3}$ peaks as for compound 1 .

Oleana-9(11),12-dien-3- $\beta$-ol (6) - The reduction of 3 with lithium aluminum hydride was carried out at described for the preparation of 4 except that the precipitate formed by adding water to the reaction mixture was dissolved by the addition of a small amount of concentrated hydrochloric acid. The product was then extracted with chloroform and the solution was dried and concentrated. TLC showed the presence of a small amount of impurity, but the major product was $6 .{ }^{13)}{ }^{1} \mathrm{H}-\mathrm{NMR}\left(100 \mathrm{MHz}, \mathrm{CDCl}_{3}\right) \delta: 0.82(3 \mathrm{H}, \mathrm{s}), 0.88(3 \mathrm{H}, \mathrm{s}), 0.90(6 \mathrm{H}, \mathrm{s}), 1.00(3 \mathrm{H}, \mathrm{s})$, $1.04(3 \mathrm{H}, \mathrm{s}), 1.16(3 \mathrm{H}, \mathrm{s}), 1.20(3 \mathrm{H}, \mathrm{s}), 3.23(1 \mathrm{H}, \mathrm{dd}, J=9$ and $5 \mathrm{~Hz}), 5.40(1 \mathrm{H}, \mathrm{d}, J=5 \mathrm{~Hz}), 5.57(1 \mathrm{H}, \mathrm{d}, J=5 \mathrm{~Hz})$.

Oxidation of 6 - Jones' reagent was added a drop at a time to a solution of $6(20 \mathrm{mg})$ in acetone $(5 \mathrm{ml})$ at $0{ }^{\circ} \mathrm{C}$ until the red-orange color persisted. Excess bisulfite was immediately added and the product extracted with chloroform. The residue remaining after evaporation of the chloroform was recrystallized from hexane to yield $\mathbf{1}$, whose spectral properties (IR, ${ }^{1} \mathrm{H}-\mathrm{NMR}$, and UV) were identical with those of the natural product. The mp's of the two samples of 1 were identical and the mixture melting point was undepressed.

Acknowledgement The authors are indebted to Dr. Nanuza L. de Menezes for identification of the plant species and to the Ministry of Planning (FINEP), the National Research Council (CNPq) and the Research Council of this University (CEPG) for financial assistance. Thanks are also due to J. B. Fernandes, Universidade Federal de São Carlos, for furnishing a part of the $\beta$-amyrin used in this research.

\section{References and Notes}

1) A. C. Pinto, A. J. R. Silva, L. M. U. Mayer and R. Braz Filho, Phytochemistry, 18, 2036 (1979).

2) A. C. Pinto, An. Acad. Brasil. Ciênc., 52, 473 (1980).

3) A. C. Pinto, L. M. M. Valente, R. S. da Silva, W. S. Garcez and P. P. da S. Queiroz, An. Acad. Brasil. Ciênc., 53, $73(1981)$.

4) A. C. Pinto and C. Borges, Phytochemistry, 22, 2011 (1983).

5) A. G. Gonzalez, B. M. Fraga and A. G. Ravelo, An. Quim., 68, 1433 (1972).

6) F. W. Wehrli and T. Nishida, Fortschritte d. Chem. Org. Naturst., 36, 1 (1979).

7) C. W. Picard and F. S. Spring, J. Chem. Soc., 1940, 1198.

8) J. H. Beynon, K. S. Sharples and F. S. Spring, J. Chem. Soc., 1938, 1233.

9) L. Ruzicka, G. Muller and H. Schellenberg, Helv. Chim. Acta, 22, 758 (1939).

10) In a forthcoming communication, oxidations of other terpenoid compounds in good yields with this reagent will be described.

11) Manuscript in preparation.

12) K. Block, Helv. Chim. Acta, 36, 1611 (1953).

13) This substance was described in ref. 7 as having a melting point of $213.5-214.5^{\circ} \mathrm{C}$. 